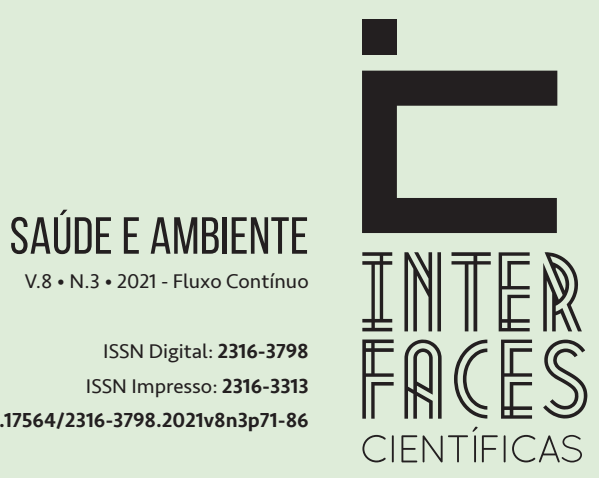

\section{UNIVERSALIZAÇÃO DO ACESSO AOS SERVIÇOS DE ESGOTAMENTO SANITÁRIO NO BRASIL E COMBATE À PANDEMIA}

UNIVERSALIZATION OF THE ACCESS TO WASTEWATER SERVICES IN BRAZIL AND COMBAT THE PANDEMIC

UNIVERSALIZACIÓN DEL ACCESO A LOS SERVICIOS DE SANEAMIENTO EN BRASIL Y COMBATE CONTRA LA PANDEMIA
Herlane Costa Calheiros ${ }^{1}$ Eleonára Ramos Reis ${ }^{2}$ Isabela Cristina Ferreira Faria ${ }^{3}$

\section{RESUMO}

Atualmente, vive-se uma pandemia mundial e, por outro lado, o Brasil enfrenta a questão da universalização do saneamento básico. Este artigo apresenta as influências do surgimento de pandemias nos tratamentos de águas residuárias e na universalização do saneamento. Foi realizada uma revisão da literatura, mostrando as principais formas de transmissão dos vírus e explica o motivo da preocupação sobre a transmissão das doenças por meio das águas residuárias, além de apresentar as maneiras para mitigar o problema da transmissão fecal-oral e fecal-inalatória. Apresenta, também, as consequências da contaminação das águas residuárias por antivirais ingeridos para tratamento de doenças durante as pandemias. De acordo com os resultados obtidos, o maior problema enfrentado é a falta de saneamento básico em muitos locais do Brasil. Se a universalização do saneamento já existisse, a população estaria mais protegida em relação a pandemia e teria uma forma de monitoramento para auxiliar no combate contra o vírus. Sendo assim, é imprescindível que os responsáveis pelos serviços de saneamento façam o tratamento adequado das águas residuárias para inativação do vírus. Para que isto ocorra o governo nos seus diversos níveis precisa fazer o seu papel de regular, investir e fiscalizar, exigindo melhorias.

\section{PALAVRAS-CHAVE}

SARS-CoV-2. 2019-nCOV. Sistema de Esgotamento Sanitário. Águas Residuárias. Tratamento de esgoto. 


\section{ABSTRACT}

Nowadays, there is a world pandemic and, on the other hand, Brazil is facing the issue of universal basic sanitation. This article presents the influences of the emergence of pandemics in the treatment of wastewater and the universalization of sanitation. A literature review was carried out showing the main forms of virus transmission and explains the reason for the concern about the transmission of diseases through wastewater, in addition to presenting ways to mitigate the problem of fecal-oral and fecal-inhalation transmission. It also presents the consequences of contamination of wastewater by anti-viral ingested to treat diseases during pandemics. According to the results obtained, the biggest problem faced is the lack of basic sanitation in many places in Brazil. If universal sanitation already existed, the population would be more protected from the pandemic and would have a form of monitoring to help combat the virus. Therefore, it is essential that those responsible for sanitation services make the appropriate treatment of wastewater to inactivate the virus. For this to happen, the government at its different levels needs to play its role of regulating, investing and inspecting, demanding improvements.

\section{KEYWORDS}

SARS-CoV-2, 2019-nCOV, sewerage system, wastewater, sewage treatment.

\section{RESUMEN}

Actualmente, hay una pandemia mundial y, por otro lado, Brasil enfrenta el tema del saneamiento básico universal. Este artículo presenta las influencias del surgimiento de pandemias en el tratamiento de aguas residuales y la universalización del saneamiento. Se realizó una revisión de la literatura que muestra las principales formas de transmisión de virus y explica el motivo de la preocupación por la transmisión de enfermedades a través de aguas residuales, además de presentar formas de mitigar el problema de transmisión fecal-oral y fecal-inhalatoria. También presenta las consecuencias de la contaminación de las aguas residuales por antivirales ingeridos para tratar enfermedades durante las pandemias. Según los resultados obtenidos, el mayor problema que se enfrenta es la falta de saneamiento básico en muchos lugares de Brasil. Si ya existiera el saneamiento universal, la población estaría más protegida de la pandemia y tendría una forma de monitoreo para ayudar a combatir el virus. Por tanto, es fundamental que los responsables de los servicios de saneamiento realicen el tratamiento adecuado de las aguas residuales para inactivar el virus. Para que esto suceda, el gobierno en sus diferentes niveles debe desempeñar su papel de regular, invertir e inspeccionar, exigiendo mejoras. 


\section{PALABRAS CLAVE}

SARS-CoV-2, 2019-nCOV, sistema de desagüe, aguas residuales, tratamiento de aguas residuales.

\section{INTRODUCÇÃO}

Com a recente globalização, os países tornaram-se hiperconectados. Porém, apesar das diversas facilidades acarretadas por esta conexão, a disseminação de doenças também se tornou mais rápida. Percebe-se o medo global crescente de pandemias virais. Em 1918, a pandemia causada pelo vírus H1N1, conhecida como gripe espanhola, causou um número de mortes de mais de 50 milhões de pessoas (TAUBENBERGER; MORENS, 2008). Desde então o mundo vem enfrentando pandemias virais como SARS, MERS e Ebola (GE et al., 2013; ECDC, 2021; WHO, 2021).

Nos dias atuais, vive-se a pandemia do vírus SARS-Cov-2, classificado desta forma pela Organização Mundial da Saúde (OMS) desde 11 de março de 2020 (SION, 2020). Esse novo coronavírus vem causando muitas vítimas e tem como principais meios de transmissão da doença as vias respiratórias e o contato direto com pessoas ou objetos contaminados (MALIK, 2020). Um dos sintomas do SARS-Cov-2 é gastrointestinal, por isso estudos têm sido realizados para verificar a presença do RNA viral nas fezes de pacientes, porém a transmissão do vírus pela via fecal-oral ainda não foi comprovada (AMIRIAN, 2020; LAROSA et al., 2020). Na atual realidade, o monitoramento das águas residuárias pode ajudar na detecção do vírus SARS-Cov-2, porém não descarta os testes clínicos em indivíduos infectados ou com suspeita de contaminação (HART; HALDEN, 2020).

Saneamento engloba uma série de ações que tem como objetivo preservar ou alterar a situação em que o meio ambiente se encontra, tendo como meta a prevenção de doenças, melhorias na qualidade de vida, na saúde e no desenvolvimento social, econômico e ambiental (INSTITUTO..., 2012).

Segundo Motta (2009), o princípio da universalização dos serviços de saneamento básico está ligado aos princípios da dignidade da pessoa humana, competência, moralidade e impessoalidade. Já Mello (2009), nos informa que a universalização é o dever de prestar os serviços públicos a toda a população, sem nenhuma distinção.

Portanto, este ensaio tem por objetivo apresentar uma reflexão sobre a importância da gestão adequada das águas residuárias frente a pandemia existente atualmente e a questão da universalização do saneamento básico, podendo identificar os problemas que estão sendo enfrentados e quais soluções podem ser tomadas para reverter esse quadro. Trata-se de um olhar panorâmico e atualizado sobre as relações entre a pandemia da COVID-19 e os serviços de saneamento no Brasil, mais especificamente com relação ao tratamento das águas residuárias, para compreender suas relações. 


\section{SANEAMENTO BÁSICO E PRINCÍPIO DA UNIVERSALIZAÇÃO}

Para que seja feita a gestão do saneamento básico no Brasil, foi promulgada a Lei Nacional de Saneamento $n^{0} 11.445 / 2007$, que estabelece diretrizes nacionais para o saneamento básico. 0 artigo $3^{\circ}$ desta Lei, apresenta que o saneamento básico engloba os serviços, a infraestrutura e instalações operacionais de abastecimento de água, esgotamento sanitário, limpeza urbana e manejos de resíduos sólidos, drenagem urbana e manejo de águas pluviais (BRASIL, 2007).

A Lei $n^{\circ}$ 11.445/2007 traz que o saneamento básico é responsável pelo esgotamento sanitário, relacionando com seus serviços, desde a sua coleta até seu lançamento final no meio ambiente. Em seu artigo $2^{\circ}$, a lei elenca os princípios fundamentais dos serviços públicos de saneamento, dentre eles está a universalização do saneamento básico (BRASIL, 2007).

Nota-se que nos países em desenvolvimento, há uma alta porcentagem de pessoas que não tem acesso as condições sanitárias básicas para o descarte de seus resíduos. Em muitas cidades, a população tem seu esgoto coletado, porém ele não passa por nenhum tratamento e é simplesmente descartado no meio ambiente, contaminando o solo, rios, lagos, mananciais, águas subterrâneas e oceanos (FUNASA, 2015).

Conforme o Diagnóstico dos Serviços de Água e Esgoto de 2018 (SNIS, 2019), no que se refere ao tratamento dos esgotos, têm-se que apenas $53,9 \%$ dos esgotos gerados são tratados, além disto, somente $60,9 \%$ dos esgotos são coletas e deste total só $74,5 \%$ são tratados. Pode-se perceber que a porcentagem de esgotos tratados no brasil é muito baixa, metade da população brasileira não tem seu esgoto tratado, e em relação a 2017 este índice teve um aumento de apenas 0,3\%. Analisando este nível por região, temos o Norte com $21,7 \%$, Nordeste com $36,2 \%$, Sudeste com $50,1 \%$, Sul com $45,4 \%$ e o Centro-Oeste com $53,9 \%$.

No dia 15 de julho desse 2020 foi criada a Lei n¹4.026/2020, ela atualiza o marco legal do saneamento básico e estimula o progresso em relação investimentos e melhoria dos serviços de água e esgoto. O principal objetivo do Novo Marco Regulatório do Saneamento Básico é universalização e qualificação dos serviços prestados no setor. A lei apresenta a inclusão de metas nos contratos de prestação de serviços, garantindo que $90 \%$ da população brasileira tenha coleta e tratamento do seu esgoto até 31 de dezembro de 2033 (BRASIL, 2020).

\section{CORONAVIRUS: COVID-19}

Os coronavírus são uma família de vírus que causam doenças em humanos e animais, em humanos ela ataca principalmente as vias respiratórias. O vírus SARS-CoV-2 é um dos sete coronavírus humanos identificados até agora e é ele o causador da doença COVID-19 (sigla em inglês, para coronavirus disease 2019). A resistência do vírus varia em relação com a temperatura, sendo maior quando exposto a temperaturas mais baixas (WEISS; NAVAS-MARTIN, 2005). 
Conforme Malta e colaboradores (2020), no Brasil a pandemia se iniciou em 26 fevereiro de 2020 e devido à ausência de vacina ela teve um crescimento exponencial, atingindo todos os estados do país.

A transmissão do COVID-19 ocorre principalmente pelo contato com gotas respiratórias, seja com pessoas infectadas ou com superfícies contaminadas (MALIK, 2020). Os sintomas apresentados são dificuldade para respirar, febre, corrimento nasal, diarreia, cansaço, tosse seca, congestão e os casos mais graves são pneumonia, insuficiência respiratória, falência renal e a morte (CHEN, N. et al., 2020; MEDEMA et al., 2020).

Na tentativa de combater a contaminação, tem-se como medida preventivas como lavar as mãos, usar máscara e a restrição social, além disto, vários municípios brasileiros e até estados fecharam suas escolas e comércios não essenciais.

A pandemia causou uma crise no sistema de saúde e retração na economia. O Banco Mundial, em relatório publicado em cinco de janeiro de 2021 (WORLD BANK, 2021), estima queda de 4,5\% no Produto Interno Bruto (PIB) brasileiro de 2020, prevê um crescimento de 3\% em 2021 apoiado pela maior confiança e condições de crédito favoráveis. No entanto, espera que o ritmo diminua no decorrer do ano, em parte devido à retirada dos estímulos monetários e fiscais, levando o PIB a 2,5\% em 2022.

\section{PRESENÇA DE VÍRUS EM ÁGUAS RESIDUÁRIAS}

Em sua pesquisa Wang e colaboradores (2005), investigaram o coronavírus SARS-CoV que foi o vírus responsável pelo surto ocorrido em 2002. O autor comprovou a presença do vírus em fezes e urinas por meio de amostras retiradas de esgoto de dois hospitais que receberam pacientes com o contágio do SARS-CoV. Com relação ao SARS-CoV-2, apesar de, até agora, a resposta imediata à pandemia tenha sido a prevenção contra a transmissão de pessoa para pessoa, a possibilidade de transmissão por meio das águas residuárias tem gerado preocupação, principalmente nos países onde o saneamento básico é precário e não há instalações de tratamento de esgoto e de água.

Diversos estudos surgem para verificar a real presença do RNA (sigla em inglês que significa ácido ribonucleico) do SARS-CoV-2 nas águas residuárias e a possibilidade de transmissão do vírus (KATAKI et al., 2021). Estudos já comprovaram a presença do vírus SARS-CoV-2 tanto em águas residuárias como em corpos hídricos superficiais. Em um relatório recente na China, o efluente de águas residuais do hospital designado para Covid-19 foi considerado positivo para o RNA de SARS-CoV-2 (XU, 2020). Ahmed e colaboradores (2020) encontraram a mesma característica genética em esgoto não tratado em uma bacia hidrográfica na Austrália.

Os genomas SARS-CoV-2 foram detectados por Wurtzer e colaboradores (2020) em efluente bruto ou tratado de uma grande Estação de Tratamento de Águas Residuárias (ETAR) na França e confirmaram que o aumento de casos de COVID-19 acarreta o aumento das unidades de genoma do vírus no esgoto. Da mesma forma, Randazzo e colaboradores (2020) relataram a ocorrência do RNA de SARS-CoV-2 em seis ETAR na Espanha, Nemudryi e colaboradores (2020) confirmaram o mesmo genoma em águas residuais nos Estados Unidos e Medema e colaboradores (2020) na Holanda. Guerrero- 
-Latorre e colaboradores (2020) identificaram a presença do vírus SARS-CoV-2 em um rio em Quito, no Equador, onde as águas residuárias são despejadas diretamente em águas naturais.

Porém, o contato direto com a água residuária contaminada ou a ingestão da mesma não é a única forma de transmissão de doenças. A presença de vírus na água aumenta a possibilidade do mesmo ser aerossolizado, particularmente durante o bombeamento de águas residuárias e sistemas de aeração (QUILLIAM et al., 2020).

Tavares e colaboradores (2020), relembram que em Hong Kong no ano de 2003, pode-se perceber que em um conjunto residencial com defeito em seu sistema de esgoto, teria relação com à erupção do SARS em grande parte dos moradores dos prédios vizinhos foram contaminados. Em Guangzhou, na China, um estudo sugeriu que a propagação do vírus SARS-CoV-2 pode ter ocorrido pelo sistema de ventilação do esgoto, que infectou três famílias que moram em apartamentos alinhados verticalmente, que possuem a mesma tubulação (CONTICINI et al., 2020).

Estudos mostram que a concentração de vírus no esgoto depende de alguns fatores como: (i) carga viral da doença na população, (ii) da composição do esgoto, que pode favorecer ou não a sobrevivência do patógeno, (iii) da temperatura, (iv) dos tratamentos adequados das águas residuárias e (v) da disposição final das mesmas (ROLLEMBERG et al., 2020).

Por isso que países menos desenvolvidos, que sofrem com a falta de infraestrutura de saneamento básico, podem ser mais suscetíveis à disseminação das rotas de transmissão fecal-oral e fecal-inalatória, sendo a exposição aos aerossóis de águas residuais contaminadas aumentada por instalações sanitárias informais e esgotos a céu aberto (GHERNAOUT; ELBOUGHDIRI, 2020; ELSAMADONY et al., 2021). Os funcionários das ETAR também estão suscetíveis a transmissão de doenças por meio da aerossolização e necessitam de equipamento de proteção individual (EPI) para a prevenção (ROLLEMBERG et al., 2020).

Um assunto preocupante é sobre o tempo de sobrevivência do SARS-CoV-2 em estações de tratamento de esgoto. Sabe-se que o vírus sobrevive mais em temperaturas baixas, então Kitajima e colaboradores (2020), apresentam em seu estudo que os coronavírus pode sobreviver em águas residuárias por até 14 dias a $4^{\circ} \mathrm{C}$, mas se a temperatura for de $20^{\circ} \mathrm{C}$ ele sobrevive somente por 72 horas.

As águas residuais contaminadas com o vírus, quando vão para os oceanos e pelo mar ser extenso, está sempre se movimentando e a água ser salgada, este vírus é diluído e consegue-se diminuir a sobrevivência do vírus. Mas foi encontrado a presença do SARS-CoV-2 em moluscos, isso é um problema, pois foi identificado a presença em um mercado de frutos do mar, local suspeito da origem do vírus SARS-CoV-2 (MORDECAI; HEWSON, 2020).

Para evitar que as águas residuárias contaminadas pelo coronavírus cheguem aos rios, mananciais e mares. Deve-se fazer um tratamento adequado, mas especificamente, uma desinfecção dessa água antes que ela seja lançada no meio ambiente (CARDUCCI et al., 2020).

No entanto, um grande problema existente é o lançamento de águas residuais nos corpos d'água sem nenhum tipo de tratamento. Conforme o Relatório do Desenvolvimento Mundial da Água da Organização das Nações Unidas (ONU) de 2017, o mundo tem-se que 80\% das águas residuárias não passam por um tratamento suficiente antes de ser lançada no meio ambiente (USMAN et al., 2020). 
Neste contexto, a pandemia da COVID-19 revela que o Brasil precisa melhorar a gestão em relação ao recurso hídrico, pois existem várias regiões em que a população não tem acesso a água tratada e nem a coleta de esgoto. Essas pessoas estão expostas a doenças por não ter direito ao saneamento básico. Por isso, deve ser priorizado a universalização do saneamento para que todo tenham os mesmos direitos, melhorando assim, a qualidade de vida e a saúde das populações mais carentes (FREITAS et al., 2020).

\section{TRATAMENTOS DE ÁGUAS RESIDUÁRIAS CAPAZES DE INATIVAR O VíruS}

Os vírus SARS-CoV são vírus envelopados que possuem uma frágil membrana e são, de certa forma, resistentes em águas residuárias, porém são menos estáveis em ambientes e mais suscetíveis a oxidantes como cloro, por exemplo. São muito sensíveis ao calor, pH extremo, luz solar e desinfetantes comuns, facilitando sua inativação (ROLLEMBERG et al., 2020; PETALA et al., 2021). De acordo com Randazzo e colaboradores (2020), tanto da etapa primária, como na etapa secundária do tratamento de águas residuárias, foi encontrado o material genético do vírus. No entanto, há tratamentos secundários de eficiência na inativação de patógenos como: as lagoas de estabilização por meio de elevado de tempo de detenção com luz solar, pH elevado e atividade biológica e as membranas de ultrafiltração que se mostram suficientes para remoção da maioria dos vírus.

Um processo muito utilizado em tratamento de águas residuárias é o sistema de lodos ativados. Alguns estudos demonstram a eficiência de remoção de vírus nesse processo. Devido a hidrofobicidade atribuída aos vírus, estes possuem a tendência em se agregar às partículas hidrofóbicas. Portanto, a adsorção dos vírus aos sólidos suspensos, seguido de sedimentação é o principal mecanismo de remoção durante o processo de lodo ativado. Este tratamento associado a ultrafiltração pode melhorar a redução do vírus ainda mais (PETALA et al., 2021).

Porém, nesse processo a inalação de aerossóis virais, durante aeração, e a exposição a resíduos e lamas contaminados podem potencialmente produzir infecções. Precauções extras devem ser tomadas para minimizar a geração de aerossóis durante o tratamento de águas residuais e o manuseio de lodo de esgoto (PETALA et al., 2021). Um dos itens que devem ser utilizados pelos funcionários das ETAR são EPI, como máscaras, protetores faciais, luvas, botas etc. (ELSAMADONY et al., 2021). Outros procedimentos podem ser tomados, quando possíveis, como cobrir a câmera de remoção de areia e o tanque de aeração para evitar a liberação de aerossóis no ar e utilizar geradores de microbolhas, que são mais adequados do que os geradores de macrobolhas, para reduzir a emissão de aerossol (TEMESGEN et al., 2017).

Em um estudo Kumar e colaboradores (2021) comprovaram a eficiência do tratamento Upflow Anaerobic Sludge Blanket (UASB), que é muito utilizado no Brasil, para remoção de vírus SARS-CoV-2. Uma amostra retirada em 27 de maio de 2020, no pico da doença na Índia, depois de passado pelo tratamento UASB, a concentração de RNA de SARS-CoV-2 foi reduzida a um nível com detecção inconclusiva. 0 mesmo estudo também não detectou nenhum gene no efluente após passado por lago de aeração e de polimento, concluindo que o sistema de tratamento convencional é eficaz na redução dos genes de SARS-CoV-2. 
A Administração de Saúde e Segurança Ocupacional dos Estados Unidos (OSHA, 2021), declara que os coronavírus são susceptíveis as mesmas condições de desinfecção que outros vírus e alega que os métodos de desinfecção já empregados nas estações de tratamento de águas residuárias sejam suficientes para a sua inativação, a saber: oxidação com hipoclorito de sódio, ácido peracético ou irradiação ultravioleta.

Outro sistema de tratamento que está sendo utilizado, pois é mais barato e requer o mínimo de qualidade de mão de obra em sua aplicação, é o cloro (GARCÍA-ÁVILA et al., 2020). Um nível de cloro livre maior do que $0,5 \mathrm{mg} / \mathrm{L}$ ou dióxido de cloro de $2,19 \mathrm{mg} / \mathrm{L}$ em águas residuárias permite a eliminação completa de SARS-CoV (KITAJIMA et al., 2020). A China, por exemplo, já solicitou o aumento do uso de cloro nos processos de desinfecção nas estações de tratamento (ZAMBRANO-MONSERRATE et al., 2020).

Porém, o cloro é transformado, no meio ambiente, em substâncias altamente perigosas para os organismos e espécies aquáticas. Por isso, a cloração excessiva pode não ser a estratégia correta para desinfecção de águas residuárias. O cloro reage com a matéria orgânica e produz compostos halogenados tóxicos que permanecem no meio ambiente por muito tempo (BULLR et al., 1990). Além disso, o efeito do cloro no meio ambiente está relacionado à redução da camada de ozônio, intimamente ligada ao aquecimento global (GARCÍA-ÁVILA et al., 2020).

Sem dúvida, os processos de maior eficiência na remoção de patógenos estão na etapa terciária do tratamento, a filtração e, principalmente, a desinfecção (RANDAZZO et al., 2020; ROLLEMBERG et al., 2020). É esta confirmação que gera grande preocupação em países menos desenvolvidos como Brasil. Na maioria das ETAR brasileiras inexistem processos de desinfecção, por serem processos mais onerosos, e, quando existem, dá-se, comumente, por meio de cloração, muitas vezes sem controle de dosagem e tempo de contato. Dessa forma, imediatamente, deve ser revista a operação das ETAR não só brasileiras, como de todos os países que estão na mesma situação, aprimorando ou acrescentando a etapa terciária no tratamento (ROLLEMBERG et al., 2020).

Pesquisadores perceberam que uma forma de prevenir a grande quantidade de RNA de SARS-CoV sendo despejada na rede de esgoto é implantar o sistema de tratamento descentralizado, que configura uma estação de tratamento em pequena escala como, hospitais, clínicas, centros de quarentena, que estão gerando águas residuárias contaminadas pelo Coronavírus. Esse sistema reduziria a carga de vírus no ambiente e interromperia qualquer transmissão secundária possível (NADDEO; LIU, 2020)

Soares e colaboradores (2020) ressaltam que a existência de contaminação das águas residuárias urbanas pelo SARS-CoV-2 deve ser considerada nas ações de vigilância para o combate à COVID-19. Por meio do monitoramento dos esgotos sanitários pode se analisar as condições das comunidades para com o vírus, permitindo tomar decisões de aumento ou diminuição de seu controle, como o distanciamento social voluntário ou até mesmo a restrição à circulação das pessoas imposta pelo governo. Para que isso seja feito corretamente as empresas prestadoras dos serviços de saneamento devem se esforçar para fornecer dados de qualidade e que ajudem na tomada de medidas no combate à pandemia.

\section{CONSEQUÊNCIAS DE INGESTÃO DE FÁRMACOS}

Outra preocupação que surge com as pandemias é o uso contínuo de antivirais pela população. Após serem ingeridos e metabolizados, os medicamentos são excretados com a urina e as fezes e 
as ETAR não foram projetadas para removê-los de maneira eficiente, uma vez que são reconhecidos como contaminantes (NANNOU et al., 2020).

Os antivirais são bioativos, uma vez despejados no meio ambiente, são potencialmente perigosos e tóxicos principalmente para a biota, como crustáceos, peixes e algas (NANNOU et al., 2020).

Outro problema trazido pelos antivirais é que podem inibir de $80 \%$ a $100 \%$ do crescimento microbiano necessário para o tratamento de águas residuais, fazendo com que a água residuária tratada não atinja os padrões de emissão exigidos pelos órgãos ambientais (REYNOLDS, 2011). Chen, W. e colaboradores (2020) mostraram que a presença de fármacos a base de cloroquina inibiu os reatores anaeróbios, reduzindo a remoção de matéria orgânica. Portanto, as ETAR devem ser otimizadas e deve ser avaliado o uso de reatores anaeróbios em sistemas que possam receber maior carga de fármacos, pois são suscetíveis a perda de performance (NANNOU et al., 2020; ROLLEMBERG et al., 2020).

\section{CONSIDERAÇÕES FINAIS}

Com este estudo pode-se destacar os seguintes aspectos:

- Os vírus que surgem com pandemias são altamente transmissíveis e muitos deles, além da transmissão respiratória, podem ser transmitidos via fecal-oral e fecal-inalatória, por meio da contaminação das águas residuárias. A preocupação é maior nos países menos desenvolvidos que possuem o saneamento básico precário e a população se torna mais suscetível às doenças virais.

- Para inativar os vírus das águas residuárias, é necessário o tratamento terciário nas ETAR. Portanto, os diversos níveis de governo e as empresas prestadoras dos serviços de saneamento precisam investir para que o tratamento de águas residuárias seja feito de forma adequada, garantindo assim mais qualidade de vida e saúde para a população.

- Deve-se levar em conta os fármacos usados nos tratamentos de doenças que são lançados nas águas residuárias e poluem o ambiente aquático. Impondo a necessidade de mudanças nas ETAR para que se sejam capazes de tratar as águas residuárias de forma a atender os requisitos ambientais, diminuindo o risco de contaminação do meio ambiente.

- Diante de uma pandemia, fica mais evidente a importância da universalização dos serviços de saneamento, principalmente no que diz respeito ao tratamento das águas residuárias, tornando crucial a atuação conjunta de União, Estados e Municípios para se alcançar essa meta, seja na criação de leis, metas, incentivos, medidas que estimulem e ações de fiscalização e monitoramento dos serviços prestados pelos responsáveis em operar os serviços de saneamento.

- Mesmo com as dificuldades enfrentadas em relação à universalização do saneamento no Brasil, o monitoramento das águas residuárias pode ajudar no combate à COVID-19, podendo ser uma ferramenta capaz de revelar a taxa de crescimento e a distribuição espacial do vírus nos municípios e auxiliar os gestores na tomada de decisões.

Portanto, por meio deste ensaio teórico, pode-se perceber a complexidade do tema. No entanto, o estudo aqui apresentado colabora para a ampliação do conhecimento do leitor, proporcionan- 
do uma reflexão crítica sobre a importância da gestão adequada das águas residuárias frente a uma pandemia e salienta a importância da universalização do saneamento básico, identificando os problemas que estão sendo enfrentados e quais soluções podem ser tomadas para reverter essa situação diante dos recentes avanços da ciência.

\section{REFERÊNCIAS}

AHMED, W. et al. First confirmed detection of SARS-CoV-2 in untreated wastewater in Australia: a proof of concept for the wastewater surveillance of covid-19 in the community. Sci Total Environ, v. 728, n. 1-8, 2020. http://dx.doi.org/10.1016/j.scitotenv.2020.138764.

AMIRIAN, E.S. Potential fecal transmission of SARS-CoV-2: current evidence and implications for public health. Int J Infect Dis, v. 95, p. 363-370, 2020. http://dx.doi.org/10.1016/j.ijid.2020.04.057

BRASIL. Lei no 11.445, de 5 de janeiro de 2007. Estabelece diretrizes nacionais para o saneamento básico. Diário Oficial da República Federativa do Brasil. Poder executivo, Brasília, DF. Disponível em: http://www.planalto.gov.br/ccivil_03/_Ato2007-2010/2007/Lei/L11445.htm. Acesso em: 26 abr. 2021.

BRASIL. Lei n 14.026 , de 15 de julho de 2020. Atualiza o marco legal do saneamento básico e altera a Lei no 9.984, de 17 de julho de 2000. Diário Oficial da República Federativa do Brasil. Poder executivo, Brasília, DF. Disponível em: https://www.planalto.gov.br/ccivil_03/_ato2019-2022/2020/ lei/l14026.htm. Acesso em: 26 abr. 2021

BULLR, J. et al. Evaluation of the health risks associated with disinfection. Crit Rev Env Control, v. 20, n. 2, p. 77-113, 1990. https://doi.org/10.1080/10643389009388392

CARDUCCI, A. et al. Making Waves: Coronavirus detection, presence and persistence in the water environment: state of the art and knowledge needs for public health. Water Res, v. 179, p. 1-9, 2020. https://doi.org/10.1016/j.watres.2020.115907

CHEN, N. et al. Epidemiological and clinical characteristics of 99 cases of 2019 novel coronavírus pneumonia in Wuhan, China: a descriptive study. Lancet, v. 395, n. 10223, p. 507-513, 2020. https:// doi.org/10.1016/S0140-6736(20)30211-7

CHEN, W. et al. Impact of long-term parental exposure to Tamiflu metabolites on the development medaka offspring (Oryzias latipes). Environ Pollut, v. 261, p. 1-9, 2020. http://dx.doi.org/10.1016/j. envpol.2020.114146 
CONTICINI, E. et al. Can atmospheric pollution be considered a co-factor in extremely high level of SARS-CoV-2 lethality in Northern Italy? Environ Pollut, v. 261, p. 1-3, 2020. http://dx.doi. org/10.1016/j.envpol.2020.114465

\section{ECDC - European Centre for Disease Prevention and Control. Communicable Disease Threats} Report - CDTR. 2021. Disponível em: https://www.ecdc.europa.eu/en/all-topics-z/threats-andoutbreaks/weekly-threats-reports-cdtr. Acesso em: 17 fev. 2021

ELSAMADONY, M. et al. Possible transmission of viruses from contaminated human feces and sewage: implications for sars-cov-2. Sci Total Environ, v. 755 (Part 1), p. 1-8, 2021. http://dx.doi. org/10.1016/j.scitotenv.2020.142575

FREITAS, D. A. F. et al. Recursos hídricos, políticas públicas e a pandemia COVID-19. Rev Ambient Água, v. 15, n. 5, p. 1-14, 2020. http://dx.doi.org/10.4136/ambi-agua.2540

FUNASA - Fundação Nacional de Saúde. Manual de saneamento. 4. ed. Brasília: Ministério da Saúde, 2015.

GARCÍA-ÁVILA, F. et al. 2020. Considerations on water quality and the use of chlorine in times of SARS-CoV-2 (COVID-19) pandemic in the community. Case St Chem Environ Eng, v. 2, p. 1-7, 2020. http://dx.doi.org/10.1016/j.cscee.2020.100049

GE, X. et al. Isolation and characterization of a bat SARS-like coronavirus that uses the ACE2 receptor. Nature, v. 503, p. 535-538, 2013. https://doi.org/10.1038/nature12711

GHERNAOUT, D.; ELBOUGHDIRI, N. Environmental Engineering for Stopping Viruses Pandemics. Open Acc Libr J, v. 7, n. 4, p. 1-17, 2020. https://doi.org/10.4236/oalib.1106299

GUERRERO-LATORRE, L. et al. SARS-CoV-2 in river water: implications in low sanitation countries. Sci Tot Environ, v. 743, p. 1-5, 2020. http://dx.doi.org/10.1016/j.scitotenv.2020.140832

HART, O. E.; HALDEN, R. U. Computational analysis of SARS-CoV-2/COVID-19 surveillance by wastewater-based epidemiology locally and globally: feasibility, economy, opportunities and challenges. Sci Tot Environ, v. 730, p. 1-9, 2020. http://dx.doi.org/10.1016/j.scitotenv.2020.138875.

INSTITUTO Trata Brasil. Manual do saneamento básico: entendendo o saneamento básico ambiental no Brasil e sua importância socioeconômica. São Paulo: Instituto Trata Brasil, 2012. Disponível em: http://www.tratabrasil.org.br/datafiles/uploads/estudos/pesquisa16/manualimprensa.pdf. Acesso em: 17 de fevereiro de 2021. 
KATAKI, S. et al. Concerns and strategies for wastewater treatment during COVID-19 pandemic to stop plausible transmission. Res Con Rec, v. 164, p. 1-18, 2021. https://doi.org/10.1016/j. resconrec.2020.105156

KITAJIMA, M. et al. SARS-CoV-2 in wastewater: state of the knowledge and research needs. Sci Total Environ, v. 739, p. 1-19, 2020. https://doi.org/10.1016/j.scitotenv.2020.139076

KUMAR, M. et al. Decay of SARS-CoV-2 RNA along the wastewater treatment outfitted with Upflow Anaerobic Sludge Blanket (UASB) system evaluated through two sample concentration techniques.

Sci Tot Environ, v. 754, p. 1-6, 2021. http://dx.doi.org/10.1016/j.scitotenv.2020.142329

LAROSA, G. et al. Coronavirus in water environments: occurrence, persistence and concentration methods - a scoping review. Water Res, v. 179, p. 1-11, 2020. http://dx.doi.org/10.1016/j.

watres.2020.115899

MALIK, Y. A. Properties of coronavirus and SARS-CoV-2. Malays J Pathol, v. 42, n. 1, p. 3-11, 2020. Disponível em: http://www.mjpath.org.my/2020/v42n1/properties-of-coronavirus.pdf. Acesso em: 17 fev. 2021.

MALTA, D. C. et al. A pandemia da COVID-19 e as mudanças no estilo de vida dos brasileiros adultos: um estudo transversal. Epidemiol Serv Saúde, v. 29, n. 4, p. 1-13, 2020. https://doi.org/10.1590/ S1679-49742020000400026

MEDEMA, G. et al. Presence of SARS-Coronavirus-2 RNA in Sewage and Correlation with Reported COVID-19 Prevalence in the Early Stage of the Epidemic in The Netherlands. Environ Sci Technol Lett, v. 7, n. 7, p. 511-516, 2020. http://dx.doi.org/10.1021/acs.estlett.0c00357

MELLO, C. A. B. Curso de direito administrativo 26. ed. São Paulo: Malheiros, 2009

MORDECAI, G. J.; HEWSON, I. Coronaviruses in the sea. Front Microbiol, v. 11, p. 1-6, 2020. https:// doi.org/10.3389/fmicb.2020.01795

MOTTA, P. R. F. A universalização como princípio fundamental do regime jurídico do saneamento básico e do Estatuto das Cidades. In: PICININ, J.; FORTINI, C. (org.). Saneamento básico: estudos e pareceres à luz da lei nº 11.445/2007. Belo Horizonte: Fórum, 2009.

NADDEO, V.; LIU, H. Editorial Perspectives: 2019 novel coronavirus (SARS-CoV-2): what is its fate in urban water cycle and how can the water research community respond? Environ Sci Water Res Technol, v. 6, n. 5, p. 1213-1216, 2020. http://dx.doi.org/10.1039/d0ew90015j 
NANNOU, C. et al. Antiviral drugs in aquatic environment and wastewater treatment plants: a review on occurrence, fate, removal and ecotoxicity. Sci Tot Environ, v. 699, p. 1-31, 2020. http://dx.doi. org/10.1016/j.scitotenv.2019.134322

NEMUDRYI, A. et al. Temporal Detection and Phylogenetic Assessment of SARS-CoV-2 in Municipal Wastewater. Cell Reports Med, v. 1, n. 6, p. 1-11, 2020. http://dx.doi.org/10.1016/j. xcrm.2020.100098

OSHA - Occupational Safety and Health Administration. COVID-19 - Control and Prevention, Solid Waste and Wastewater Management Workers and Employers. 2021. Disponível em: https://www. osha.gov/coronavirus/control-prevention/solid-waste-wastewater-mgmt. Acesso em: 17 fev. 2021.

PETALA, M. et al. A physicochemical model for rationalizing SARS-CoV-2 concentration in sewage. Case study: the city of thessaloniki in greece. Sci Tot Environ, v. 755, p. 1-10, 2021. http://dx.doi. org/10.1016/j.scitotenv.2020.142855

QUILLIAM, R. S. et al. COVID-19: the environmental implications of shedding sars-cov-2 in human faeces. Environ Int, v. 140, p. 1-2, 2020. http://dx.doi.org/10.1016/j.envint.2020.105790

RANDAZZO, W. et al. SARS-CoV-2 RNA in wastewater anticipated COVID-19 occurrence in a low prevalence area. Water Res, v. 181, p. 1-8, 2020. http://dx.doi.org/10.1016/j.watres.2020.115942

REYNOLDS, K.A. Trade-offs to pandemic disease treatment: impact of increased use of medicines and water quality. Water Cond Purific Magazine, 20 maio 2011. Disponível em: http://wcponline. com/2011/05/20/trade-offs-pandemic-disease-treatment-impact-increased-use-medicines-waterquality-2/. Acesso em: 17 de fevereiro de 2021

ROLLEMBERG, S. et al. Avaliação da contaminação, sobrevivência e remoção do coronavírus em sistemas de tratamento de esgoto sanitário. Rev Tecnol, v. 41, n. 1, p. 1-15, 2020. http://dx.doi.org/1 $0.5020 / 23180730.2020 .10849$

SION, A.O. Necessidade de investimentos em infraestrutura para Universalização do Saneamento Básico no combate a pandemias: uma análise do enfrentamento à COVID-19 à luz do Novo Marco Legal do Saneamento Básico. Rev Ciên Juríd Soc - IURJ, v. 1, n. 1, p. 111-141, 2020. https://doi. org/10.47595/2675-634X.2020v1i1p111-141

SNIS - Sistema Nacional de Informações sobre Saneamento. $\mathbf{2 4}^{\circ}$ Diagnóstico dos Serviços de Água e Esgoto. Secretaria Nacional de Saneamento: Brasília. 2019. Disponível em: http://www.snis.gov. br/downloads/diagnosticos/ae/2018/Diagnostico_AE2018.pdf. Acesso em: 17 fev. 2021. 
SOARES, A. F. S. et al. Vigilância do sistema de esgotamento sanitário e o novo coronavírus (SARSCoV-2) no Brasil: uma discussão necessária. Ciências da Saúde. Scielo Preprint, version 1, p. 1-15, 2020. Disponível em: https://preprints.scielo.org/index.php/scielo/preprint/view/469/590. Acesso em: 17 fev. 2021.

TAUBEnBERGER, J. K.; MORENS, D. M. The pathology of influenza virus infections. Ann Rev Pathol Mech Dis, v. 3, p. 499-522, 2008. https://doi.org/10.1146/annurev.pathmechdis.3.121806.154316

TAVARES, M. J. L. et al. Anthropic actions and the emergence of pandemics: what is the role of environmental engineering in this context? Res Soc Develop, v. 9, n. 8, p. 1-17, 2020. https://doi. org/10.33448/rsd-v9i8.6727

TEMESGEN, T. et al. Micro and nanobubble technologies as a new horizon for water-treatment techniques: a review. Adv Colloid Interfac, v. 246, p. 40-51, 2017. http://dx.doi.org/10.1016/j. cis.2017.06.011

USMAN, M. et al. Existence of SARS-CoV-2 in wastewater: implications for its environmental transmission in developing communities. Environ Sci Technol, v. 54, n. 13, p. 7758-7759, 2020. https://doi-org.ez38.periodicos.capes.gov.br/10.1021/acs.est.0c02777

WANG, $X$. et al. Study on the resistance of severe acute respiratory syndrome associated coronavirus. J Virol Methods, v. 126, n. 1-2, p. 171-177, 2005. https://doi.org/10.1016/j. jviromet.2005.02.005

WEISS, S. R.; NAVAS-MARTIN, S. Coronavirus pathogenesis and the emerging pathogen severe acute respiratory syndrome coronavirus. Microbiol Mol Biol Rev, v. 69, n. 4, p. 635-664, 2005. https://doi. org/10.1128/MMBR.69.4.635-664.2005

WHO - World Health Organization. Coronavirus disease (COVID-19) weekly epidemiological update and weekly operational update. Situation Reports, 2021. Disponível em: https://www.who.int/ emergencies/diseases/novel-coronavirus-2019/situation-reports. Acesso em: 17 fev. 2021.

WORLD BANK. Global economic prospects. World Bank: Washington, DC, jan. 2021. Disponível em: https://www.worldbank.org/pt/publication/global-economic-prospects. Acesso em: 17 fev. 2021.

WURTZER, S. et al. Evaluation of lockdown impact on SARS-CoV-2 dynamics through viral genome quantification in Paris wastewaters. MedRxiv Preprint, p. 1-13, 2020. http://dx.doi.org/10.1101/20 20.04.12.20062679 
XU, Z. Medical wastewater treatment in COVID times. China Water Risk Publ., 17 abr. 2020.

Disponível em: https://www.chinawaterrisk.org/resources/analysis-reviews/medical-wastewatertreatment-in-covid-times/. Acesso em: 17 fev. 2021.

ZAMBRANO-MONSERRATE, M. et al. Indirect effects of COVID-19 on the environment. Sci Total Environ, v. 728, p. 1-4, 2020. https://doi.org/10.1016/j.scitotenv.2020.138813 
2 Mestranda em Engenharia Hídrica pela UNIFEI.

E-mail: nararamos33@gmail.com

3 Mestranda em Engenharia Hídrica pela UNIFEI.

E-mail: isacrisff.exp@gmail.com

\section{(). (1) (-)}

Este artigo é licenciado na modalidade acesso abertosob a Atribuição-Compartilhalgual CC BY-SA

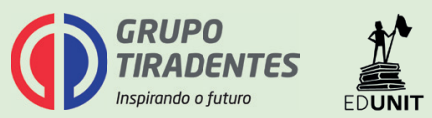

